\section{DELAYED PRIMARY REPAIR OF INTRATHORACIC ESOPHAGEAL PERFORATION: IS IT SAFE?}

The management of intrathoracic esophageal perforation with delayed diagnosis is a subject of controversy. Because of the obvious advantages of primary repair as a simple single-stage operation, this technique was preferentially used to treat 18 of 22 consecutive patients with esophageal perforation. These patients were stratified into three groups according to the time interval between perforation and repair: group $A$, less than 6 hours, five patients (28\%); group B, 6 to 24 hours, six patients (33\%); and group C, more than 24 hours, seven patients (39\%). Group A patients were older $(p<0.05)$ and group $B$ had fewer iatrogenic perforations $(B, 17 \%$; $A$, $80 \% ; \mathrm{C}, 57 \%, p<0.1)$. Additional tissue was used to buttress the repair site in all three groups $(\mathrm{A}, 3 / 5$ patients, $60 \% ; \mathrm{B}, 4 / 6$ patients, 67\%; $\mathrm{C}, 6 / 7$ patients, $86 \% ; p=$ not significant). In seven patients $(39 \%)$, a fundic wrap was used to reinforce the site of primary repair. The outcomes of the three groups were analyzed. Group $A$ had the lowest proportion of postoperative leaks (A, $0 / 4$ patients, $0 \% ; \mathrm{B}, 4 / 6$ patients, $67 \%$;, $5 / 6$ patients, $83 \% ; p<$ 0.05 ) and postoperative morbidity $(A, 2 / 5$ patients, $40 \% ; B, 6 / 6$ patients, $100 \%$; $\mathrm{C}, 6 / 7$ patients, $86 \% ; p<0.1$. However the increased incidence of leak and morbidity did not lead to an increase in mortality. One death occurred in each group, with an overall mortality of $17 \%$ (A, 1/5 patients, $20 \% ; \mathrm{B}, 1 / 6$ patients, $17 \% ; \mathrm{C}, 1 / 7$ patients, $14 \% ; p=$ not significant). We conclude that in the era of advanced intensive care capabilities, primary repair of intrathoracic esophageal perforation can be safely accomplished in most patients regardless of the time interval between perforation and operation. Leakage at the suture site is common unless primary repair is carried out without delay. Postoperative leakage, however, is usually inconsequential and does not necessarily result in an adverse outcome. (J Thorac Cardiovasc Surg 1996;111:114-22)

Nan Wang, $\mathrm{MD}^{\mathrm{a}}$ (by invitation), Anees J. Razzouk, MD ${ }^{\mathrm{a}}$ (by invitation), Ali Safavi, MD ${ }^{a}$ (by invitation), Karen Gan, MD $^{a}$ (by invitation), Glen S. Van Arsdell, $\mathrm{MD}^{\mathrm{a}}$ (by invitation), Petrina M. Burton, RN ${ }^{\mathrm{a}}$ (by invitation), Bryan L. Fandrich, $\mathrm{MD}^{\mathrm{a}}$ (by invitation), Michael J. Wood, MD ${ }^{\text {a }}$ (by invitation), Arthur C. Hill, MD (by invitation), Edwin E. Vyhmeister, $\mathrm{MD}^{\mathrm{a}}$ (by invitation), Rodrigo Miranda, $\mathrm{MD}^{\mathrm{b}}$ (by invitation), Changwoo Ahn, $\mathrm{MD}^{\mathrm{b}}$ (by invitation), and Steven R. Gundry, MD, Loma Linda and Fontana, Calif.
From the Departments of Surgery, Loma Linda University Medical Center, Loma Linda, Calif., ${ }^{a}$ and Kaiser Permanente Medical Center, Fontana, Calif. ${ }^{\text {b }}$

Read at the Seventy-fifth Annual Meeting of The American Association for Thoracic Surgery, Boston, Mass., April 23-26, 1995.

Address for reprints: Nan Wang, MD, Assistant Professor of Surgery, Division of Cardiothoracic Surgery, Department of Surgery, Loma Linda University Medical Center, 11234 Anderson St., Loma Linda, CA 92354.

Copyright $(1996$ by Mosby-Year Book, Inc.

$0022-5223 / 96 \$ 5.00+0 \quad \mathbf{1 2 / 6 / 6 9 2 5 5}$
The diagnosis of intrathoracic esophageal perforation is frequently delayed. Longer time intervals between perforation and intervention will often result in greater mediastinal soilage. When the perforation is more than 24 hours old, primary repair of the esophagus has generally not been recommended. ${ }^{1-7}$ Instead, a multitude of alternative approaches, such as drainage alone or in combination with diversion of the esophagus (with or without esophageal exclusion) or resection of the esophagus, have been advocated to treat this subset of patients. $^{4-12}$ Unfortunately, these approaches have 
Table I. Patient characteristics

\begin{tabular}{|c|c|c|c|c|}
\hline Variable & $\begin{array}{c}\text { Group } A \text { : } \\
\quad<6 h r \\
(n=5)\end{array}$ & $\begin{array}{c}\text { Group } B: \\
6-24 h r \\
(n=6)\end{array}$ & $\begin{array}{c}\text { Group C: } \\
>24 h r \\
(n=7)\end{array}$ & $\begin{array}{c}\text { All patients } \\
(n=18)\end{array}$ \\
\hline Age (yr) & $77 \pm 12^{*}$ & $59 \pm 12$ & $63 \pm 11$ & $66 \pm 13$ \\
\hline Male & $2(40 \%)$ & $4(67 \%)$ & $6(86 \%)$ & $12(67 \%)$ \\
\hline Iatrogenic & $4(80 \%)$ & $1(17 \%) \dagger$ & $4(57 \%)$ & $9(50 \%)$ \\
\hline Dilation for reflux stricture & 2 & & 1 & $3(17 \%)$ \\
\hline Dilation for achalasia & & & 2 & $2(11 \%)$ \\
\hline Dilation for DES & 1 & & & $1(6 \%)$ \\
\hline Esophagoscopy & 1 & 1 & & $2(11 \%)$ \\
\hline Esophageal obturator & & & 1 & $1(6 \%)$ \\
\hline Noniatrogenic & $1(20 \%)$ & $5(83 \%) \dagger$ & $3(43 \%)$ & $9(50 \%)$ \\
\hline Boerhaave syndrome & $1(20 \%)$ & $3(50 \%)$ & $3(43 \%)$ & $7(39 \%)$ \\
\hline Foreign body & & $2(33 \%)$ & & $2(11 \%)$ \\
\hline
\end{tabular}

$D E S$, Diffuse esophageal spasm.

${ }^{*} p<0.05$.

$\uparrow p<0.1$.

not uniformly improved outcome. Indeed, in many series these alternative methods of treatment have been associated with high mortality rates of $25 \%$ to $40 \% .^{4-9,13-15}$ Furthermore, in most instances these approaches have the disadvantage of needing further reconstructive operations to reestablish esophageal continuity.

In 1975, Grillo and Wilkins ${ }^{16}$ recommended that primary repair of an esophageal perforation should be undertaken whenever possible, regardless of the time interval between perforation and intervention. In the past 10 years, that attitude has prevailed and rarely has an esophagus been encountered that was damaged beyond repair. With proper exposure of the injury site, the mucosal and submucosal layers are almost always viable and sturdy enough for a careful suture reapproximation. In 22 consecutive patients with nonmalignant intrathoracic esophageal perforations, 18 patients had such primary repair of their perforations. We have reviewed our experience to determine if the time interval between perforation and repair had an influence on the subsequent outcomes in these patients.

\section{Patients and method}

The records of all patients who had undergone repair of an esophageal perforation between 1986 and 1994 at Loma Linda University Medical Center, Loma Linda, and Kaiser Permanente Medical Center, Fontana, were reviewed. Affiliation between the two institutions within the same residency teaching program has resulted in a similar approach to the treatment of esophageal perforation. After exclusion of patients with cervical perforations and postesophagectomy anastomotic leaks, a total of $22 \mathrm{pa}$ tients with intrathoracic perforations were identified. Eighteen of these patients had a primary repair of their perforations. The other four patients were treated by esophageal exclusion $(n=3)$ or esophageal resection $(n=1)$.

Primary repair. Of the 18 patients, there were 12 men and six women between the ages of 43 and 93 years (mean 66 years). In nine patients (50\%) the perforations resulted from iatrogenic causes: esophagoscopy to insert a nasogastric tube $(n=1)$, esophagoscopy to remove a foreign body $(n=1)$, intraoperative esophageal dilation $(n=1)$, esophagoscopy and dilation of peptic stricture $(n=3)$, pneumatic dilation for achalasia $(n=2)$, and insertion of an esophageal obturator $(n=1)$. The other $50 \%$ had the following causes for perforation: postemetic perforation (Boerhaave's syndrome) in seven patients $(39 \%)$ and foreign body-induced perforation in two patients $(11 \%)$. The time interval between esophageal perforation and primary repair varied from 4 hours to 13 days. These patients were divided into three groups according to the time interval between perforation and repair (Table I). Group A consisted of five patients (28\%) in whom the diagnosis of esophageal perforation was immediately established and the repair was accomplished within 6 hours. This was a significantly older group with a mean age of 77 years $(p<0.05)$. Four of five patients $(80 \%)$ in this group had an iatrogenic perforation. Group B consisted of six patients $(33 \%)$ in whom the repair was delayed by less than 24 hours but more than 6 hours. This group had the lowest proportion of perforations from iatrogenic causes (one patient, $17 \% ; p<0.1$ ). Group $\mathrm{C}$ consisted of seven patients $(39 \%)$ in whom the repair was delayed by more than 24 hours. In this group, there was a nearly even distribution between iatrogenic and noniatrogenic causes for perforation. In four patients the delay was greater than 2 days ( 2.5 days, 3.5 days, 5 days, and 13 days). The first of these patients had a pneumatic dilation of the distal esophagus for achalasia. An esophageal tear was suspected early but was incorrectly assessed by an esophagogram as being a contained, intramural type of perforation. The patient was medically treated for 2 days before operative intervention. The second patient had a cardiac 
Table II. Operative procedures

\begin{tabular}{|c|c|c|c|c|}
\hline Variable & $\begin{array}{c}\text { Group } A \\
<6 h r \\
(n=5)\end{array}$ & $\begin{array}{c}\text { Group B: } \\
6-24 h r \\
(n=6)\end{array}$ & $\begin{array}{c}\text { Group C: } \\
>24 h r \\
(n=7)\end{array}$ & $\begin{array}{c}\text { All patients } \\
(n=18)\end{array}$ \\
\hline Left thoracotomy & $5(100 \%)$ & $6(100 \%)$ & $4(57 \%)$ & $15(83 \%)$ \\
\hline Repair buttressed & $3(60 \%)$ & $4(67 \%)$ & $6(86 \%)$ & $13(72 \%)$ \\
\hline Fundic wrap & 3 & 2 & 2 & $7(39 \%)$ \\
\hline Pericardial fat & & & 3 & $3(17 \%)$ \\
\hline Diaphragmatic flap & & 1 & 1 & $2(11 \%)$ \\
\hline Intercostal muscle & & & 2 & $2(11 \%)$ \\
\hline Pleural patch & & 1 & & $1(6 \%)$ \\
\hline Additional procedure & $3(60 \%)$ & $1(17 \%)$ & $3(43 \%)$ & $7(39 \%)$ \\
\hline Bougienage dilation & 2 & 1 & 1 & $4(22 \%)$ \\
\hline Myotomy & 1 & 0 & 2 & $3(17 \%)$ \\
\hline
\end{tabular}

arrest from an acute myocardial infarction. He was resuscitated by the emergency medical technicians, who used an esophageal obturator to facilitate mechanical ventilation during cardiopulmonary resuscitation. The initial attention to the patient was focused on his cardiac care. $\mathrm{He}$ was transferred to us when esophageal perforation from the obturator was discovered 3 days later. The third patient had an acute abdominal condition. Diagnosis of postemetic esophageal perforation (Boerhaave syndrome) was considered only when the patient failed to recover from a normal abdominal exploration. He was also transferred to us for definitive treatment. The final patient had the longest time interval between perforation and repair. Profound sepsis developed while he was being treated for a presumptive diagnosis of pneumonia. Esophageal perforation (Boerhaave syndrome) was unrecognized for almost 2 weeks. He was eventually transferred to us in a state of septic shock.

Repair technique. The esophageal perforation was approached via a left thoracotomy incision in 15 patients and a right thoracotomy incision in three patients (Table II). Right thoracotomy approach was chosen in the three patients with midesophageal perforation who also had an effusion predominantly on the right side. Esophageal repair consisted primarily of débridement of devitalized tissue, exposure of the retracted mucosal and submucosal edges, and suture closure of these edges in one or two layers with a variety of interrupted, nonabsorbable sutures. The repair was generally performed over a $50 \mathrm{~F}$ Maloney dilator. The mediastinal and pleural spaces were then débrided and drained. Decortication was frequently necessary.

Intraoperative bougienage dilation of concomitant stricture was necessary in four patients (22\%), and myotomy of the esophagus, 180 degrees from the perforation, was also performed in three patients (17\%). Further reinforcement of the repair was carried out in 13 patients $(72 \%)$. The various tissue reinforcements (Table II) were performed to buttress the primary suture line so as to provide a secondary barrier to potential postoperative leak. This adjunctive measure was more frequently applied in the group B (67\%) and group C (86\%) patients.

Exclusion or resection. Primary repair was not attempted in two patients because of anatomic constraints. One patient (delay $<6$ hours) with iatrogenic perforation required resection because the esophagus was severely scarred from prior esophageal operations. Another patient with Boerhaave syndrome (delay 48 hours) had a densely adherent mediastinum from previous bilateral thoracotomies. A transthoracic approach to the esophagus was deemed more hazardous than an exclusion procedure through the neck and abdomen. Only two patients were not treated by primary repair because of the surgeon's preference. Both patients (delays 12 and 72 hours) had Boerhaave syndrome and were treated by esophageal diversion and exclusion. In only one patient was there a bias against primary repair on the basis of treatment delay beyond 24 hours.

Statistical analysis. The clinical outcomes of the three groups of patients were analyzed by univariate comparisons by means of the Fisher exact test or the $\chi^{2}$ analysis for discrete variables and the unpaired Student's $t$ test for continuous data. Specifically, the outcome variables examined were esophageal leak, postoperative sepsis, overall morbidity, and mortality. Esophageal leak was defined as any leak, including minute, contained leaks, at the suture site if demonstrated by a postoperative esophagogram $(n=15)$ or at autopsy $(n=1)$. Sepsis was defined as signs of septic syndrome (fever, tachycardia, hypotension, respiratory distress). Mortality was defined as any in-hospital deaths. Because of the small sample size in this series, multivariate analysis was not possible. All statistical calculations were performed by the SPSS 4.0 software package (SPSS, Inc., Chicago, Ill.) on the Macintosh computer (Apple Computer, Cupertino, Calif.).

\section{Results}

The clinical presentation varied considerably according to the cause of the esophageal perforation. The majority of patients with iatrogenic perforation $(n=9)$ had either immediate diagnosis (group A, $n=4$ ) or "late" diagnosis (group C, $n=4$ ). No patient with iatrogenic perforation in group $\mathrm{A}$ or $\mathrm{B}$ ( $<24$ hours) had sepsis (Table III). Only in late iatrogenic perforations (group $C$ ) was there any evidence of preoperative sepsis $(50 \%)$.

In contrast, patients with Boerhaave syndrome 

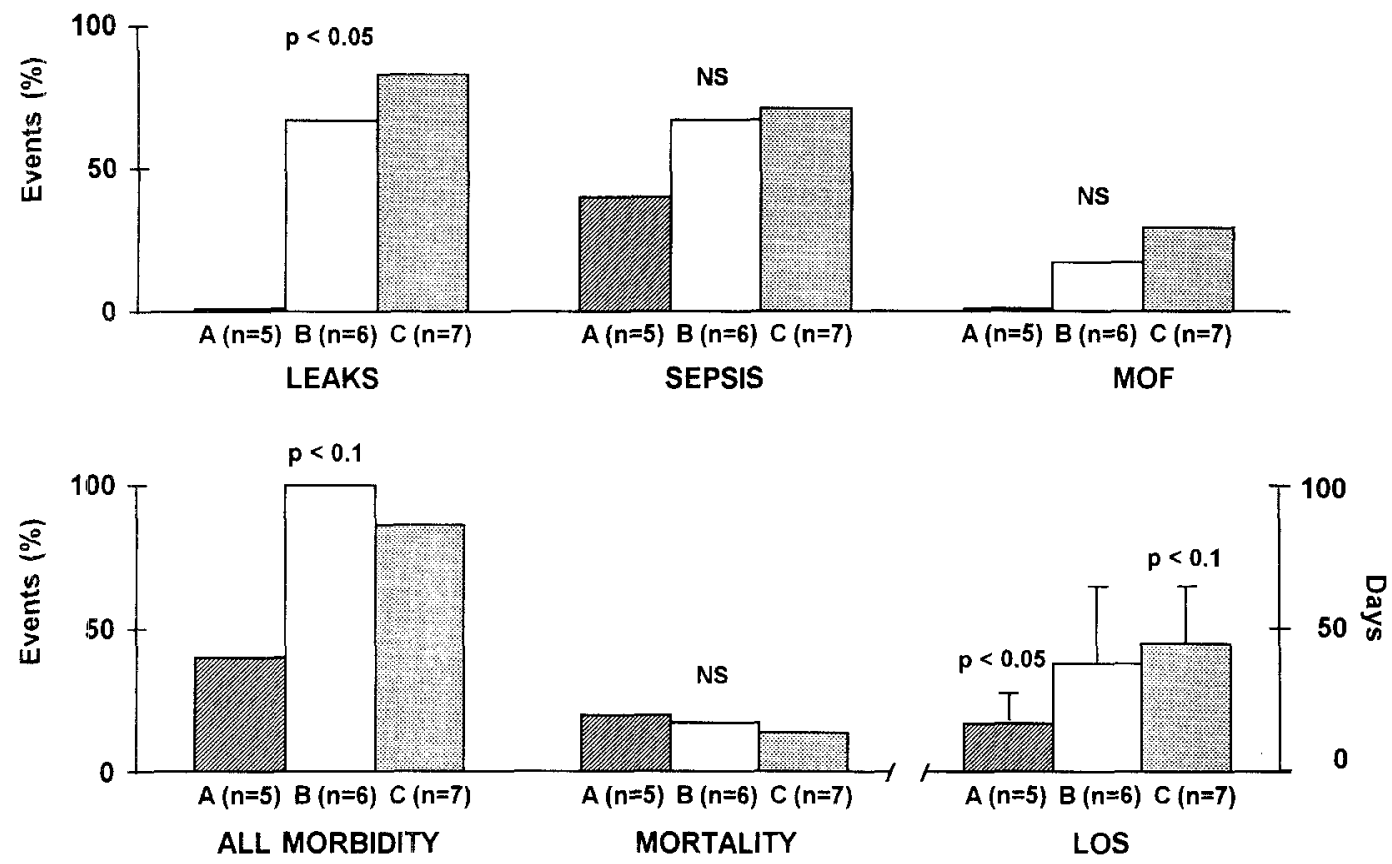

MOF $=$ Multiple Organ Failure
LOS $=$ Length of Hospital Stay

Fig. 1. Postoperative morbidity and mortality. MOF, Multiple organ failure; LOS, length of hospital stay.

Table III. Preoperative sepsis

\begin{tabular}{ccccc}
\hline Group & $\begin{array}{c}\text { All perforation } \\
(n=18)\end{array}$ & $\begin{array}{c}\text { Iatrogenic } \\
\text { perforation } \\
(n=9)\end{array}$ & $\begin{array}{c}\text { Boerhaave } \\
\text { perforation } \\
(n=7)\end{array}$ & $\begin{array}{c}\text { Foreign } \\
\text { body } \\
(n=2)\end{array}$ \\
\hline Group A $(n=5)$ & $1 / 5(20 \%)$ & $0 / 4(0 \%)$ & $1 / 1(100 \%)$ & - \\
Group B $(n=6)$ & $2 / 6(33 \%)$ & $0 / 1(0 \%)$ & $2 / 3(67 \%)$ & $0 / 2(0 \%)$ \\
Group C $(n=7)$ & $4 / 7(57 \%)$ & $2 / 4(50 \%)$ & $2 / 3(67 \%)$ & - \\
All patients $(n=18)$ & $7 / 18(39 \%)$ & $2 / 9(22 \%)$ & $5 / 7(71 \%)^{*}$ & $0 / 2(0 \%)$ \\
\hline
\end{tabular}

*p $<0.05$.

$(n=7)$ rarely were referred to us early enough for immediate diagnosis (group A, $n=1$ ). Most of these patients $(71 \%)$ were also in a septic condition when referred for treatment $(p<0.05)$, and the occurrence of preoperative sepsis appeared to be independent of the time interval between perforation and repair (Table III).

The most frequently used tissue to buttress the repair was a fundic wrap (modified Nissen fundoplication). This wrap was used exclusively in all seven esophageal perforations that were confined to the distal esophagus at the level of the diaphragmatic hiatus. All three patients with reflux strictures were included in this subset. The other perforations treated in this manner were Boerhaave syndrome $(n=2)$, endoscopic perforation $(n=1)$, and pneumatic dilation for achalasia $(n=1)$.

Morbidity. Postoperative esophageal leak occurred in nine patients $(50 \%)$ ). Leaks were significantly less common in group A than in the other groups: $0 \%$ versus $67 \%$ (group B) and $83 \%$ (group C), $p<0.05$ (Fig. 1). All four leaks in group B were small and contained. They resolved without further intervention. However oral feeding and chest drain removal were delayed for a longer period in these group $\mathrm{B}$ patients. The leaks in group $\mathrm{C}$ were more complicated: Additional percutaneous closed drainage under computed tomographic guidance was required in two patients, open drainage was performed in one patient, and proximal esophageal 
Table IV. Univariate predictors of esophageal leaks, postoperative sepsis, overall morbidity, and mortality

\begin{tabular}{llcr}
\hline Outcome & \multicolumn{1}{c}{ Variable } & Incidence & $p$ Value \\
\hline Leaks & No fundic wrap & $89 \%$ (vs 14\%-fundic wrap) & $<0.01$ \\
& Time to repair $>6 \mathrm{hr}$ & $75 \%$ (vs 0\%-<6 hr) & 0.02 \\
Sepsis & Preop. sepsis & $100 \%$ (vs 36\%-no preop. sepsis) & 0.01 \\
Morbidity & Time to repair $>6 \mathrm{hr}$ & $92 \%$ (vs 40\%-<6 hrs) & 0.04 \\
& Noniatrogenic & $100 \%$ (vs 57\%-iatrogenic) & 0.04 \\
& Male & $92 \%$ (vs 50\%-female) & 0.08 \\
& Preop. sepsis & $100 \%$ (vs 64\%-no preop. sepsis) & 0.11 \\
Bortality & No significant predictor & $100 \%$ (vs 64\%-non-Boerhaave) & 0.11 \\
\hline
\end{tabular}

diversion was needed in one patient. All of these patients survived with completely intact esophageal continuity except for the one patient who required temporary proximal esophageal diversion. This patient with Boerhaave syndrome had a stricture at the repair site associated with peptic ulcerations from previously undiagnosed gastroesophageal reflux. $\mathrm{He}$ required several subsequent esophageal dilations as an outpatient to reestablish normal swallowing function. The only other significant predictor of esophageal leak was the lack of a fundic wrap (Table IV). Of the seven patients treated by the addition of a fundic wrap, only one patient (14\%) had a postoperative leak $(p<0.05)$. This was a patient with achalasia in group $\mathrm{C}$ whose leak resolved spontaneously.

Postoperative sepsis occurred in 11 patients $(61 \%)$. The incidence of sepsis was completely unrelated to the time interval between perforation and repair (see Fig. 1). The only predictor of postoperative sepsis was preoperative sepsis (see Table IV). All seven patients who were in a septic condition before the operation remained in a septic condition after the operation $(p<0.05)$. Postoperative sepsis without septic shock, however, was not associated with subsequent mortality.

The overall morbidity rate was high (78\%). Morbidity was less (see Fig. 1) in group A patients and in patients with iatrogenic perforation (see Table IV) regardless of group $(57 \%, p<0.05)$. Only four patients (group A, $n=3$; group $\mathrm{C}, n=1$ ) had an uneventful hospital course. All of these patients had iatrogenic perforations. As expected, the length of hospital stay was shorter in group A ( $16 \pm 7$ days, $p<0.05)$ than in either group B (38 \pm 25 days) or group C ( $45 \pm 17$ days).

Mortality. Postoperative in-hospital death occurred in three patients with primary repair $(17 \%)$. One death occurred in each group (see Fig. 1). In group A, perforation occurred in one patient who had an intraoperative dilation of the esophagus for benign stricture and diffuse esophageal spasm. The injury was immediately recognized and repaired, but this 87-year-old patient had a massive stroke and was later allowed to die of pneumonia despite a successful repair. The other two patients (one each in groups B and C) died of sepsis caused by their perforations. Both patients had Boerhaave syndrome and were essentially moribund from septic shock, requiring moderate doses of vasopressors before the operation for hemodynamic support. Subsequent autopsy in one patient revealed an intact esophageal repair with no evidence of leak.

Only one of the four patients treated by resection or exclusion survived (mortality rate $75 \%$ ). This was the patient in whom primary repair was not selected because of delay in treatment ( 72 hours). Although she ultimately recovered, she had a prolonged and complicated hospital course because of persistent sepsis.

Follow-up. Follow-up information was available in 13 of the 15 survivors ( $87 \%$ ). The mean follow-up period was 65 months (5 to 129 months). There was one late death, at 4 years, the result of a myocardial infarction. Besides the patient with Boerhaave syndrome who had severe gastroesophageal reflux resulting in a stricture, two other patients had mild reflux symptoms (Boerhaave, $n=1$; achalasia, $n=$ 1). All responded well to medical treatment. No patient required reoperation on the esophagus. Symptoms of dysphagia and gas-bloat syndrome were not present in any of the patients, including all of the six surviving patients who had a fundic wrap.

\section{Discussion}

In 1724 , Boerhaave ${ }^{17}$ produced the first classic description of a distal esophageal rupture, which had occurred following violent vomiting after an overindulgence in food and drink. Not until 1947 were successful repairs of such perforations reported by Barrett ${ }^{18}$ and by Olsen and Clagett. ${ }^{19}$ Over the next 40 years, surgical treatment of this 
potentially lethal condition has evolved substantially, with numerous operative alternatives having been developed. ${ }^{14-20}$ To date, however, the best strategy in the management of intrathoracic esophageal perforation is still widely debated, particularly when the diagnosis of the perforation is delayed.

Historically, primary repair of late perforations ( $>24$ hours old) have yielded dismal results. ${ }^{1-7}$ The presence of massive inflammation from corrosive digestive enzymes and gross bacterial contamination in the mediastinum commonly observed with late perforations has promulgated the notion that any primary repair performed under such circumstances will most likely fail. Recently, however, there is increasing evidence that primary repair affords the patient the best probability of survival, regardless of the time interval between esophageal perforation and repair. ${ }^{13-15,21,22}$ In 1975, Grillo and Wilkins ${ }^{16}$ reported on four patients with intrathoracic esophageal perforations who were treated successfully by reinforced primary repair with a pleural patch. The perforations in two of these patients were more than 24 hours old. Their series was recently expanded in 1995 by Wright and associates ${ }^{23}$ to include 28 patients. Primary repair in these patients, including $46 \%$ with late ( $>24$ hours) diagnosis, resulted in an overall mortality of $14 \%$ with no deaths from failure of the repair technique. Whyte, Iannettoni, and Orringer $^{22}$ also reported excellent results in 22 patients (iatrogenic perforations, $n=18$; Boerhaave syndrome, $n=4$ ) in whom primary repair of the perforation was done with staples. Even though the repair was delayed by more than 24 hours in $41 \%$ of the patients, the overall mortality rate was only $5 \%$.

In the past 10 years, we have adopted a similar nonselective approach ${ }^{22}$ to the treatment of patients with intrathoracic esophageal perforation. As a rule, we have not found the layer of strength, namely the mucosal-submucosal layer, to be compromised beyond repair in any of the patients when devitalized tissue was débrided properly.

Only three of the 18 patients with primary repair died in the postoperative period (16\% mortality rate), with only one death in the group with delayed ( $>24$ hours) repairs. Death was unrelated to the time interval between perforation and repair.

Postoperative morbidity, however, is a common occurrence after primary repair $(78 \%)$. Because a broad definition of morbidity was used, only four patients were completely free of any postoperative morbidity such as sepsis or esophageal leak. Significant $(p<0.05)$ risk factors for increased morbidity were delayed diagnosis (groups B and C) and noniatrogenic perforation. Of the 14 patients with postoperative morbidity, seven patients (Boerhaave perforation, $n=5$; iatrogenic perforation, $n=2$ ) were already in a septic condition before the operation. The overall high morbidity rate, however, did not correlate with a high mortality rate. It did reflect on the increased complexity of care that was necessary in most of these patients to effect ultimate survival. With aggressive intensive nursing care, early nutritional support, and a proper antibiotic regimen, all but the two patients with septic shock survived the complicated postoperative course.

Primary repair of the esophagus is not advisable in all situations. Besides malignant disease, an esophagus that is severely damaged from certain benign intrinsic conditions (scleroderma, previous caustic burn) or extrinsic trauma (acute lye ingestion, blast injury) is not usually salvageable. A nondilatable stricture (grade IV reflux esophagitis) or a nonfunctioning esophagus (stage III achalasia) is probably best treated by esophageal resection. ${ }^{24}$ Nonetheless, most benign strictures or motility disorders do not contraindicate primary repair. In our experience, all three of the benign strictures from reflux esophagitis were successfully dilated concomitantly and two patients with achalasia were also successfully treated by a myotomy opposite the repair site. Late follow-up in these patients with associated procedures was available in all but one patient with reflux esophagitis. No patient had dysphagia, and mild reflux symptoms occurred in one patient with achalasia.

One final clinical consideration may also contraindicate primary repair as the initial procedure of choice. The only patients who had died as a direct consequence of esophageal perforation were the two patients with Boerhaave syndrome who were in profound shock requiring moderate doses of vasopressors (12- to 24-hour delay in one patient; 13-day delay in the other). In such a patient, safe anesthetic management for a formal thoracotomy approach may be impossible. Perhaps a nonthoracotomy approach to drain the mediastinal and pleural spaces and to exclude the esophagus ${ }^{10,12}$ would be initially preferable. Such an operation may diminish mediastinal contamination enough for septic shock to become responsive to medical management. Primary repair of the esophagus may still be staged when such a patient's hemodynamic and ventilatory status has improved sufficiently to allow a thoracotomy procedure. 
A few technical details of primary repair should be emphasized. Wide débridement and proper drainage of the mediastinal and pleural spaces are absolutely necessary ${ }^{21-23}$ Stapling of the perforation has also been described recently and is associated with a low rate of postoperative leak $(15 \%$ to $18 \%){ }^{22,25}$ Regardless of the closure technique, the mucosal-submucosal layer must be clearly identified for meticulous approximation, because this is the main layer of strength in the repair.

As others have recommended, ${ }^{13-15,23}$ use of autologous tissue to reinforce the repair appeared beneficial in our experience, especially in group B and $\mathrm{C}$ patients. Although the various autologous tissues did not reduce the incidence of postoperative leak significantly, they appeared effective in diminishing the severity of mediastinal contamination. Of the 13 patients with tissue reinforcement, the majority $(85 \%)$ had either no leak $(n=6)$ or a very small, contained leak $(n=5)$.

In our experience, use of a fundic wrap as a reinforcing tissue was particularly gratifying. Only one leak occurred in the seven patients treated with a fundic wrap. We think the fundic wrap has the potential to function as a serosal patch if the primary closure fails. Furthermore, by eliminating gastroesophageal reflux, the fundic wrap not only is beneficial to patients with primary reflux but may, in fact, promote healing of the repaired esophagus in all patients. Recent evidence ${ }^{7,26}$ suggests that new pathologic reflux can develop, even in patients with Boerhaave syndrome, because of motility disturbance resulting from the distal esophageal perforation. Such an occurrence was suspected in one of our patients. $\mathrm{We}^{27}$ have found that adding a fundic wrap to the primary esophageal repair is relatively simple, and there were no significant undesirable late sequelae. However the fundic wrap can be used only for perforations in the vicinity of the diaphragmatic hiatus.

In conclusion, the time interval between perforation and operative intervention should not prejudice the surgeon against primary repair of an intrathoracic esophageal perforation. Other clinical variables, such as severe irreversible intrinsic esophageal disease (including malignant tumors and nondilatable stricture) and preoperative sepsis accompanied by profound hemodynamic and respiratory instability, are more pertinent to the decision process. In our experience, postoperative leak was common unless primary repair was accomplished without any delay. However, if the primary suture line was reinforced with autologous tissue, particularly a fundic wrap, most of these leaks were benign clinical events and none proved fatal.

\section{REFERENCES}

1. Rosoff L, White EJ. Perforation of the esophagus. Am J Surg 1974;128:207-8.

2. Sawyers JL, Lane CE, Foster JH, Daniel RA. Esophageal perforation: an increasing challenge. Ann Thorac Surg 1975;19:233-8.

3. Finley RJ, Pearson FG, Weisel RD, Todd TR, Ilves R, Cooper J. The management of nonmalignant intrathoracic esophageal perforations. Ann Thorac Surg 1980;30:571-83.

4. Skinner DB, Little AG, DeMeester TR. The management of esophageal perforation. Am J Surg 1980;139: 760-4.

5. Goldstein LA, Thompson WR. Esophageal perforations: a 15 year experience. Am J Surg 1982;143:495503.

6. Bladergroen MR, Lower JE, Postlethwait RW. Diagnosis and recommended management of esophageal perforations and rupture. Ann Thorac Surg 1986;42: 235-9.

7. Salo JA, Isolauri JO, Heikkila LJ, et al. Management of delayed esophageal perforation with mediastinal sepsis: Esophagectomy on primary repair? J THORAC CARDiovasc Surg 1993;106:1088-91.

8. Abbott OA, Mansour KA, Logan WD, Hatcher CR, Symbas PN. Atraumatic so-called "spontaneous" rupture of the esophagus: a review of 47 personal cases with comments on a new method of surgical therapy. J Thorac Cardiovasc Surg 1970;59:67-83.

9. Sarr MG, Pemberton JH, Payne WS. Management of instrumental perforations of the esophagus. J THORAC Cardiovasc Surg 1982;84:211-8.

10. Urschel C, Razzuk MA, Wood RE, Galbraith N, Pockey M, Paulson PL. Improved management of esophageal perforation: exclusion and diversion in continuity. Ann Surg 1974;179:587-91.

11. Lee YC, Lee ST, Chu SH. New technique of esophageal exclusion for chronic esophageal perforation. Ann Thorac Surg 1991;51:1020-2.

12. Bardini R, Bonavina L, Pavarello M, Asolati M, Peracchia A. Temporary double exclusion of the perforated esophagus using absorbable staples. Ann Thorac Surg 1992;54:1165-7.

13. Attar S, Hankins JR, Suter CM, Coughlin TR, Sequeira A, McLaughlin JS. Esophageal perforation: a therapeutic challenge. Ann Thorac Surg 1990;50:4551.

14. Gouge TH, Depan HJ, Spencer FC. Experience with the Grillo pleural wrap procedure in 18 patients with perforation of thoracic esophagus. Ann Surg 1989; 209:612-9.

15. Richardson JD, Martin LF, Borzotta AP, Polk HC. 
Unifying concepts in treatment of esophageal leaks. Am J Surg 1985;149:157-62.

16. Grillo HC, Wilkins EW. Esophageal repair following late diagnosis of intrathoracic perforation. Ann Thorac Surg 1975;20:387-99.

17. Boerhaave H. Atrocis, nec descripti prius, morbi historia secundem artis leges conscripta, lugduni batavorum, bontes teniana. Medici 1724:60.

18. Barrett NR. Report of a case of spontaneous rupture of the esophagus successfully treated by operation. $\mathrm{Br}$ J Surg 1947;35:216-7.

19. Olsen AM, Clagett OT. Spontaneous rupture of the esophagus: report of a case with immediate diagnosis and successful surgical repair. Postgrad Med 1947;2: 417-9.

20. Jones WG, Ginsberg RJ. Esophageal perforation: a continuing challenge. Ann Thorac Surg 1992;53:53443.

21. Ohri SK, Liakakos TA, Pathi V, Townsend ER, Fountain SW. Primary repair of iatrogenic thoracic esophageal perforation and Boerhaave's syndrome. Ann Thorac Surg 1993;55:603-6.

22. Whyte RI, Iannettoni MD, Orringer MB. Intrathoracic esophageal perforation: the merit of primary repair. J Thorac Cardiovasc Surg 1995;109:140-6.

23. Wright CD, Mathisen DJ, Wain JC, Moncure AC, Hilgenberg $\mathrm{AD}$, Grillo $\mathrm{HC}$. Reinforced primary repair of thoracic esophageal perforation. Ann Thorac Surg 1995;60:245-9.

24. Orringer MB, Stirling MC. Esophagectomy for esophageal disruption. Ann Thorac Surg 1990;49:35-43.

25. Gayet B, Breil P, Fekete F. Mechanical sutures in perforation of the thoracic esophagus as a safe procedure in patients seen late. Surg Gynecol Obstet 1991;172:125-8.

26. Salo JA, Seppala KM, Pitkaranta PP, Kivilaakso EO. Spontaneous rupture and functional state of the esophagus. Surgery 1992;112:897-900.

27. Safavi A, Wang N, Razzouk AJ, et al. One-stage primary repair of distal esophageal perforation using fundic wrap. Am Surg 1995;10:919-24.

\section{Discussion}

Dr. Mark B. Orringer (Ann Arbor, Mich.). In 1975 Hermes Grillo and Earle Wilkins ${ }^{1}$ recommended that primary repair of intrathoracic esophageal perforations be undertaken whenever possible, regardless of the interval from injury to operation. Old dogma is slow to die, but clearly a new era has dawned that supports this concept.

Several recent series have demonstrated that despite delays in repair beyond 24 hours in $39 \%$ to $79 \%$ of patients, satisfactory outcomes can be achieved, with mortality rates averaging $9 \%$ (Discussion Table $\mathrm{I}$ ). ${ }^{2-5}$ The reported leak rates after primary repair have been too high, however, $50 \%$ in the series just described by Dr. Wang. Although the majority of these leaks are relatively easily managed and ultimately heal, they add
Discussion Table I. Primary repair of intrathoracic esophageal perforations

\begin{tabular}{lrrrrrl}
\hline & \multicolumn{1}{c}{$\begin{array}{c}\text { Repair } \\
\text { Report }\end{array}$} & No. Iatrogenic & $\begin{array}{c}\text { Repair } \\
\text { reinforced }\end{array}$ & $\begin{array}{c}\text { Leak } \\
\text { rate }\end{array}$ & Mortality \\
\hline Gouge $^{2}$ & 14 & $6(43 \%)$ & $11(79 \%)$ & $11(79 \%)$ & $2(14 \%)$ & 0 \\
Ohri $^{3}$ & 9 & $5(55 \%)$ & $5(55 \%)$ & 0 & $3(30 \%)$ & $1(10 \%)$ \\
Whyte $^{4}$ & 22 & $18(82 \%)$ & $9(41 \%)$ & $5(23 \%)$ & $4(18 \%)$ & $1(5 \%)$ \\
Wright $^{5}$ & 28 & $10(36 \%)$ & $13(46 \%)$ & $28(100 \%)$ & $7(25 \%)$ & $4(14 \%)$ \\
Wang* $^{*}$ & 18 & $9(50 \%)$ & $7(39 \%)$ & $13(72 \%)$ & $9(50 \%)$ & $3(17 \%)$ \\
\hline
\end{tabular}

*Indicates paper under discussion.

days of hospitalization and morbidity. Several groups, including Dr. Wang's, advocate buttressing the repair to prevent leaks and minimize sequelae when leaks do occur. The emphasis, however, must be on meticulous technique of repair rather than on what is used to cover the suture line. ${ }^{4}$ [Slide] The pouting torn mucosa is grasped and adjacent muscle separated from underlying submucosa. A vertical esophagomyotomy above and below exposes the entire limits of the tear. A circumferential rim of normal submucosa around the entire defect is evident. [Slide] Stay sutures elevate normal submucosa into the jaws of an ENDO GIA stapler (Auto Suture Company Division, United States Surgical Corporation, Norwalk, Conn.), which leaves a watertight, three-layered, stapled closure when the stapler is fired. Adjacent muscle is approximated over the staple suture line and provides all the reinforcement that is necessary. Our group has achieved primary healing in $82 \%$ of such repaired esophageal perforations. ${ }^{4}$ Dr. Wang has emphasized a number of important concepts in treating these patients: (1) Iatrogenic perforations are detected earlier than spontaneous ruptures; (2) the success rate for primary repair of iatrogenic perforations is greater; and (3) when an associated stricture is present, obstruction distal to the repair must be relieved.

Dr. Wang, I have some specific questions about your report:

1. In our experience, repair over a $50 \mathrm{~F}$ dilator, which you advocate, may prevent a tension-free approximation of the inflamed torn esophagus. We thus prefer to do the repair over a $40 \mathrm{~F}$ to $46 \mathrm{~F}$ dilator. Have you experienced difficulty suturing the tear with a $50 \mathrm{~F}$ dilator in the esophagus, and could this be a factor in your $50 \%$ leak rate?

2. I question your suggestion that, particularly in patients in septic shock, tube thoracostomy drainage and exclusion of the esophagus without thoracotomy may be more appropriate than an attempt at primary repair. As a rule, such patients are dying as a result of undrained mediastinal contamination, and the "too sick for an operation" approach may deny them optimal mechanical cleansing of the mediastinum and chest and the best chance for survival.

3. In a patient with no reflux and an iatrogenic distal esophageal perforation, is it justified to enter the free peritoneal cavity to mobilize the stomach for a fundoplication, thereby spreading the intrathoracic sepsis into the abdomen? 
I commend you for your long-term follow-up, with a mean of 65 months. Such long-term functional results after repair of esophageal perforations are not widely available.

\section{REFERENCES}

1. Grillo $\mathrm{H}$, Wilkins $\mathrm{E}$. Esophageal repair following late diagnosis of intrathoracic perforation. Ann Thorac Surg 1975;20:387-99.

2. Gouge T, Depan H, Spencer F. Experience with the Grillo pleural wrap procedure in 18 patients with perforation of thoracic esophagus. Ann Surg 1989;209:612-9.

3. Ohri S, Leikakos T, Pathi V, Townsend I, Fountain W. Primary repair of iatrogenic esophageal perforation and Boerhaave's syndrome. Ann Thorac Surg 1993;55:605-6.

4. Whyte RI, Iannettoni MD, Orringer MB. Intrathoracic esophageal perforation: the merit of primary repair. Ann Thorac Surg 1995;109:140-6.

5. Wright CD, Mathisen DJ, Wain JC, Moncure AC, Hilgenberg AD, Grillo HC. Reinforced primary repair of thoracic esophageal perforation. Ann Thorac Surg [In press].

Dr. Wang. We do advocate performing the repair over a $50 \mathrm{~F}$ dilator, I guess for fear of narrowing the esophagus after the repair. As others have pointed out, there is a genuine concern for esophageal stricture after primary repair. The other reason we use a $50 \mathrm{~F}$ dilator is that in seven of our patients, the dilator allowed us to perform a loose Nissen fundoplication procedure.

The staple technique was recently brought to our attention by your series and we have not tried this particular method. Again, we have some concern for esophageal narrowing when the closure is performed over a $40 \mathrm{~F}$ dilator.

The two patients in profound shock in our series did not survive, but not because of failure in the operation; they were in shock going into the operating room with elements of adult respiratory distress syndrome. It is hard enough to treat these patients in the intensive care unit, and to treat them in the operating room with single lung ventilation is even more difficult. We are only advocating not opening the chest initially until some effort in treating septic shock has taken place. A simple diversion of saliva and gastric content may temporary improve the situation in these extreme cases.

The fundoplication procedure in our experience has been most effective in that only one patient had a leak, which was very small. Our series consisted of a very large proportion of patients with Boerhaave syndrome, and that perhaps influenced the leak rate in our experience.

\section{1-800-55-MOSBY}

This number links you to the full text of articles published in over 25,000 journals, including all Mosby journals. MOSBY Document Express $^{\circledR}$, a rapid response information retrieval service, provides quick turnaround, 24-hour availability, and speedy delivery methods. For inquiries and pricing information, call our toll-free, 24-hour order line: 1-800-55-MOSBY; outside the United States: 415-259-5046; fax: 415-259-5019; E-mail: mosbyexp@class.org. 